\title{
Removal of trivalent chromium ions from aqueous solutions by Sodium polyacrylate beads
}

\author{
Abdelkarim Ouass ${ }^{1,2^{*}}$, Lamya Kadiri ${ }^{1}$, Youness Essaadaoui ${ }^{1}$, Rida Allah Belakhmima ${ }^{3}$, Mohammed \\ Cherkaoui $^{2}$, Ahmed Lebkiri , El Housseine Rifi ${ }^{1}$ \\ ${ }^{1}$ Laboratory of Organic Synthesis and Extraction Processes, Ibn Tofail University - Faculty of Sciences, PO \\ Box.133 - 14000- Kenitra, Morocco \\ ${ }^{2}$ Laboratory of Materials, Electrochemistry and Environment(LMEE), Department of Chemistry - Ibn Tofail \\ University - Faculty of Sciences, PO Box.133 - 14000- Kenitra, Morocco \\ ${ }^{3}$ Center of Analysis, Expertise, Transfer of Technology and Incubation (CUAE2TI) - University Ibn Tofail - \\ Faculty of Sciences, Kenitra, Morocco
}

\begin{abstract}
In the present study, the performance of sodium polyacrylate beads on the removal of trivalent chromium $\mathrm{Cr}$ (III) from aqueous solutions was evaluated using several techniques such as Fourier Transformed Infrared Spectroscopy (FTIR), Scanning Electron Microscopy (SEM) and Energy Dispersive X-ray Analysis (EDAX), Inductively Coupled Plasma (ICP) and Atomic Adsorption Spectroscopy (AAS). On one hand, the characterization of dry PANa beads was carried out through FTIR and the surface morphology was analyzed by SEM and EDAX methods in order to show the loading of heavy metal on PANa beads. On the other hand, the effect of contact time, initial $\mathrm{pH}$ solution, initial $\mathrm{Cr}$ (III) concentration, adsorbent mass and temperature on the adsorption capacity of PANa was studied. All results have shown that the adsorption equilibrium was reached at about 60 minutes with an adsorption efficiency close to $90 \%$. Also, the study of the reliability of PANa beads was effectuated using $0.01 \mathrm{M}$ nitric acid solution through six cycles of adsorption/desorption which were determined in order to study the reliability of PANa over time and to test their efficiency in industrial applications. Finally, the obtained thermodynamic parameters $\left(\Delta \mathrm{G}^{\circ}, \Delta \mathrm{H}^{\circ}\right.$ and $\left.\Delta \mathrm{S}^{\circ}\right)$ indicate that the adsorption process is spontaneous and endothermic.
\end{abstract}

Keywords: trivalent chromium, Adsorption, Sodium polyacrylate, thermodynamic parameters.

\section{Introduction}

The presence of heavy metals in the environment that caused by discharges of industrial wastewater is behind considerable damage to the natural balance of the aquatic ecosystem when they are above certain concentrations 1,2 . Chromium exists in the environment in two forms of stable oxidation states: $\mathrm{Cr}$ (III) and $\mathrm{Cr}(\mathrm{VI})^{3,4}$. Literature has shown that it is widely used in the surface treatment industry and in the tannery, textiles, wood processing, agriculture ${ }^{5,6}$. $\mathrm{Cr}$ (III) is known as an essential dietary supplement in human nutrition field that helps for metabolism of lipids, carbohydrates and protein and is also considered an essential element for the regulation of insulin ${ }^{7-9}$. Cr (VI) salts with greater mobility and solubility in water ${ }^{10,11}$ are more toxic than $\mathrm{Cr}$ (III). However, at high concentrations as a result of their accumulation, $\mathrm{Cr}$ (III) becomes toxic to aquatic ecosystems, living organisms, plants and humans.

*Corresponding author: Abdelkarim Ouass

Email address: abdelkarim.ouass@uit.ac.ma

DOI: http://dx.doi.org/10.13171/mjc72/01808051520-ouass
To reduce the impact of water pollution, several separation techniques have been used, including chemical precipitation ${ }^{12,13}$, ion exchange resins ${ }^{14-16}$, membrane filtration ${ }^{17}$, electrocoagulation ${ }^{18,19}$, coagulation ${ }^{20}$. Nevertheless, these techniques have certain disadvantages that limit their applications, in particular, the cost and the life duration of membranes, slow kinetics and secondary contamination. The search for new supports capable to eliminate heavy metals from aqueous solutions has a crucial importance given a large number of potential applications. Last decades, a great importance was attached to the adsorption of metal ions on polymeric supports especially synthetic beads ${ }^{21,22}$, which are low cost, eco-friendly and available materials, which offer fast and easy application in wastewaters treatment ${ }^{23-25}$.

Sodium polyacrylate is a part of the compounds of polyelectrolytes ionizable groups capable to be dissociated in a polar solvent (usually water). The presence of charged groups increases solubility

Received June 24, 2018

Accepted, July 2, 2018

Published August 5, 2018 
chains and has an important role in industrial applications and in biological processes, agriculture, hygiene products, medicine, pharmaceuticals, the cosmetics industry and the paper industry or also the oil industry, recovery of elements harmful to the environment, as heavy metals is an important application field.

This article is devoted to studying the removal of chromium (III) by adsorption on sodium polyacrylate beads prepared by swelling sodium polyacrylate beads in distilled water. After characterization of the polymer used as an adsorbent agent by FTIR spectroscopy, the kinetic and thermodynamic studies of the adsorption of chromium ions by PANa hydrogel were carried out. In fact, the study of the influence of various parameters (contact time, aqueous solution $\mathrm{pH}$, adsorbent mass, initial heavy metal concentration, temperature) on the $\mathrm{Cr}$ (III) binding performance on the gel in order to optimize the adsorption process. The determination of thermodynamic parameters $\left(\Delta \mathrm{G}^{\circ}, \Delta \mathrm{H}^{\circ}\right.$ and $\left.\Delta \mathrm{S}^{\circ}\right)$ has described and defined the type of adsorption process.

\section{Material and Methods}

\section{Preparation of adsorbent}

The studied adsorbent is a sodium polyacrylate polymer whose the structure is represented in Fig. 1. These polymers are capable of retaining up to 200 times their weight in water and which are available in the transparent spherical form, non-porous surface appearance, whose diameter varies between 2 and $3.5 \mathrm{~mm}$ and marketed under the name: SEVEN COLOR CRYSTAL BOLL, reference SJQ-007. They are provided by Xinchang Chengtan Magic Bean \& Grass Artware Doll Factory of Origin Company: Zhejiang, China. These materials have several advantages such as low cost, easy implementation and chemical stability in a wide $\mathrm{pH}$ range.

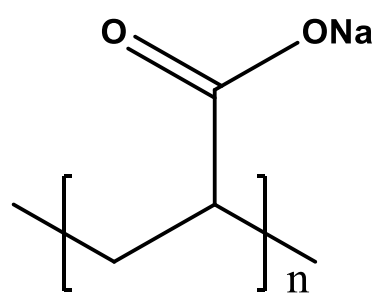

Figure 1. The structure of sodium polyacrylate (PANa)

PANa beads were introduced into a beaker containing $100 \mathrm{ml}$ of distilled water for 8 hours in order to reach the limit swelling, and then they were recovered from the solution and weighed again.
PANa beads mass was calculated through the rate of swelling (swollen PANa mass / dry polymer mass).

\section{Preparation of aqueous solution}

Aqueous solutions were prepared from high quality of hydrated chromium nitrate salt $\left(\mathrm{Cr}\left(\mathrm{NO}_{3}\right)_{3}\right.$, $\left.9 \mathrm{H}_{2} \mathrm{O}\right)$. The stock solutions were then used to obtain the working solutions through dilution with double distilled water. Fresh dilutions were prepared and used for each experiment. The initial $\mathrm{pH}$ of working solutions was adjusted using $0.1 \mathrm{~N} \mathrm{HNO}_{3}$ or $0.1 \mathrm{~N}$ $\mathrm{NaOH}$ solutions.

\section{Experimental techniques}

The chromium concentrations of the obtained samples were measured by Atomic Absorption Spectroscopy (AAS) (air/acetylene) at $240.7 \mathrm{~nm}$ on a spectrometer of Jena 350 AA Spectrometer type and Inductively Coupled Plasma Optical Emission Spectrometer (ICP-OES, Perkin Elmer Optima, USA). The $\mathrm{pH}$ of solutions was controlled by a $\mathrm{pH}$ meter (HANNA, Model-8417).

\section{Adsorption experiments}

Experiments were carried out to study the effect of different parameters on the adsorption of chromium by PANa beads. In fact, a swollen PANa bead mass which is equal to $7.5 \mathrm{~g}$ corresponds to $0.035 \mathrm{~g}$ of dry PANa was placed in a thermoregulated cell at $25{ }^{\circ} \mathrm{C}$ containing $100 \mathrm{ml}$ of aqueous solution containing $10 \mathrm{ppm}$ of chromium ions. The experimental setup adopted for this work is illustrated in Fig. 2 and consists of a double-walled glass cell containing the metal solution, controlled by a thermometer, a glass electrode connected to a $\mathrm{pH}$ meter and a magnetic stirrer. At time $\mathrm{t}=0$, beads were immersed in the metal solution. Samples were then taken at regular time intervals from the aqueous phase. Each sample has been diluted in the case of its concentration does not exceed the calibration range of the spectrometer used for the determination of metal ions.

- The adsorption efficiency of chromium fixed by the gel is calculated from (Eq. 1):

$\mathbf{R} \%=\frac{\mathrm{C}_{0}-\mathrm{C}_{\mathrm{e}}}{\mathrm{C}_{\mathbf{0}}} \times \mathbf{1 0 0}$

$\mathrm{C}_{0}$ and $\mathrm{C}_{\mathrm{e}}$ are the initial and the equilibrium concentrations of $\mathrm{Cr}$ (III) respectively.

- The number of chromium ions retained on a mass unit of coriander seeds is calculated from (Eq. 2):

$\mathbf{Q}=\frac{\text { Mole number of fixed } \mathrm{Cr}^{3+}}{\text { Mole number of } \mathrm{COO}^{-}}$ 


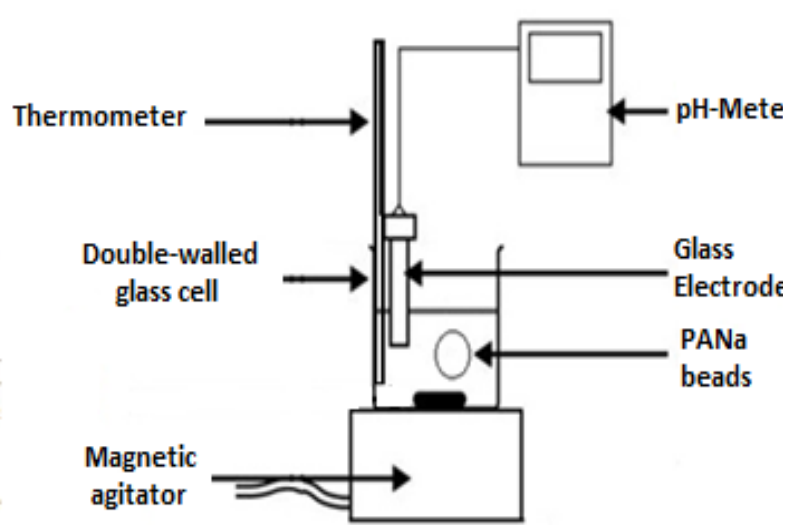

Figure 2. Experimental set-up adopted for adsorption experiments

\section{Results and Discussion}

Characterization of PANa beads by FTIR

The FTIR spectra of PANa beads were carried out using a Vertex 70 Fourier transform FTIR spectrophotometer at a rate of 400 to $4000 \mathrm{~cm}^{-1}$ with a resolution of $4 \mathrm{~cm}^{-1}$. The characteristic spectrum of the gel before and after adsorption of chromium ions is shown in (Fig. 3). FTIR study was effectuated in order to determine specific functional groups that

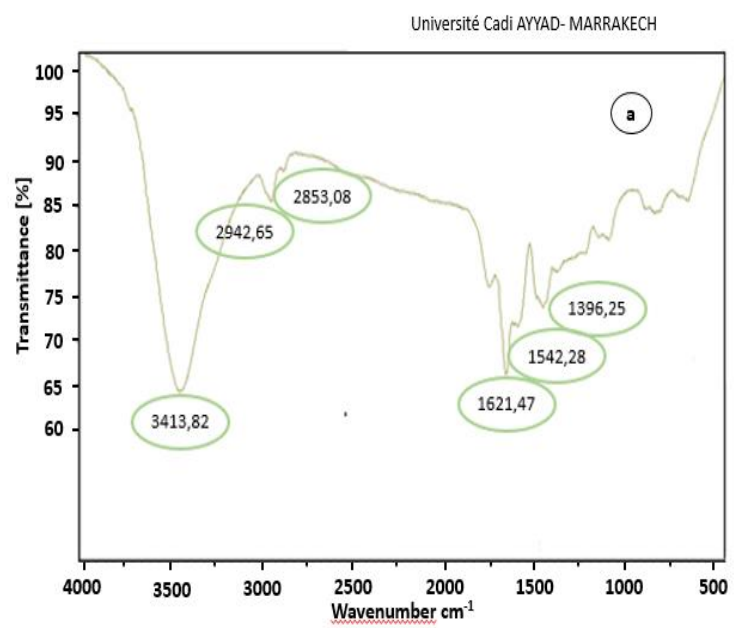

PANa beads contain. The study of this spectrum has revealed a broad peak at $3413.82 \mathrm{~cm}^{-1}$ which is attributed to the $\mathrm{OH}$ stretching of the water of hydration molecules in the superabsorbent polymer (PANa) ${ }^{26}$. The vibrations at $2942.65 \mathrm{~cm}^{-1}$ and $2853.08 \mathrm{~cm}^{-1}$ correspond to the asymmetric and symmetric stretching of the curvatures in the $-\mathrm{CH}_{2}$ and $\mathrm{CH}$ - plane, which indicates the existence of a main PANA polymer chain ${ }^{27}$. In addition, a band was observed at $1542.28 \mathrm{~cm}^{-1}$ this peak can be attributed to the asymmetric stretching vibrations $-\mathrm{C}=\mathrm{O}$ of $-\mathrm{COO}^{-}$groups ${ }^{28}$. The peak at $1621.47 \mathrm{~cm}^{-1}$ corresponds to the stretch $\mathrm{C}=\mathrm{O}$ of the acrylate units. The infrared spectra of the polymers also contain other bands in the region of $1396.25 \mathrm{~cm}^{-1}$ attributed to the stretching vibration of $-\mathrm{COO}^{-}$group ${ }^{29}$. This Analysis has shown the existence of Sodium polyacrylate characteristic groups in the microstructure of PANa beads that is a very important seat for the removal of metal ions. The comparison, of both of FTIR spectra of PANa samples before (Fig.3a) and after extraction of chromium ions (Fig.3b), has shown an important difference corresponding to the band intensity values of the obtained peaks.

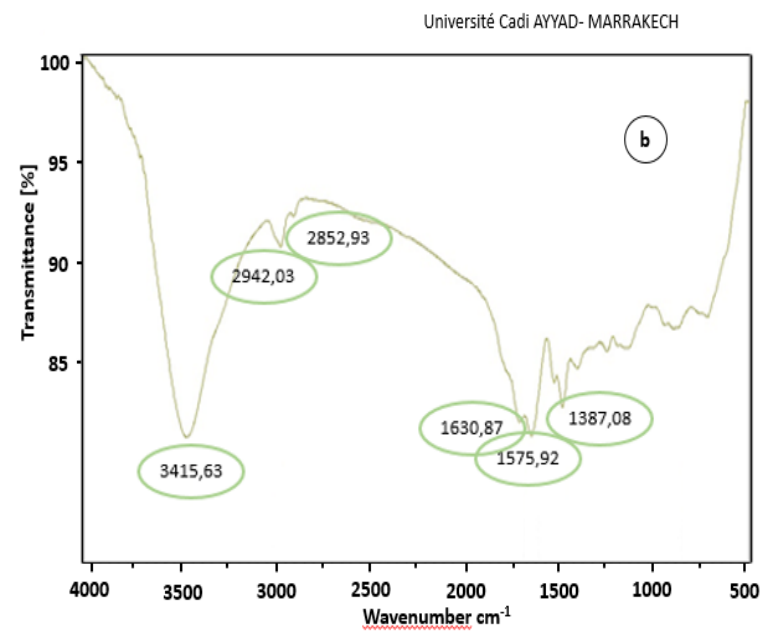

Figure 3. FTIR spectra of dry PANa beads before (a) and after (b) adsorption of chromium ions

The most intense peak at about $1621.47 \mathrm{~cm}^{-1}$, which was attributed to the $\mathrm{C}=\mathrm{O}$ stretching of the acrylate molecules, has moved to a lower wavenumber $1630.87 \mathrm{~cm}^{-1}$. The adsorption band saved at $1542.28 \mathrm{~cm}^{-1}$ corresponding to asymmetric stretching vibrations $-\mathrm{C}=\mathrm{O}-\mathrm{COO}^{-}$groups has moved to $1575.92 \mathrm{~cm}^{-1}$. In addition, the adsorption bands attributed to the stretching vibration of the carboxylate group - $\mathrm{COO}^{-}$have also increased from $1396.25 \mathrm{~cm}^{-1}$ to $1387.08 \mathrm{~cm}^{-1}$ that indicate the reorganisation of these groups in the polymer. In fact, these functional groups are responsible for the adsorption of trivalent chromium ions, as their chelating ability.
SEM and EDAX analysis of PANa beads surface

In order to characterize the surface morphology and texture of PANa beads in the absence and the presence of $\mathrm{Cr}$ (III), the scanning electron microscopy (SEM) and Energy Dispersive X-ray analysis were performed using VEGA3 TESCAN. The obtained images at a resolution of $5 \mu \mathrm{m}$ are illustrated in the Fig. 4. It can be clearly seen that the surface of the gel (PANa) is highly porous, rough and irregular (Fig. 4a). This surface was completely modified after the adsorption process (Fig. 4b), which is may be covered with chromium ions. To determine the present elements and to understand the nature of the formed film on the adsorbent surface, EDAX analysis was carried out (Fig. 5). The 
obtained spectra, before adsorption of $\mathrm{Cr}$ (III), make it possible to deduce that the major components of the hydrogel are carbon, oxygen and sodium (Fig. 5a). After the adsorption mechanism, the $\mathrm{Na}$ peak intensity was decreased and several peaks corresponding to $\mathrm{Cr}$ (III) have appeared on PANa

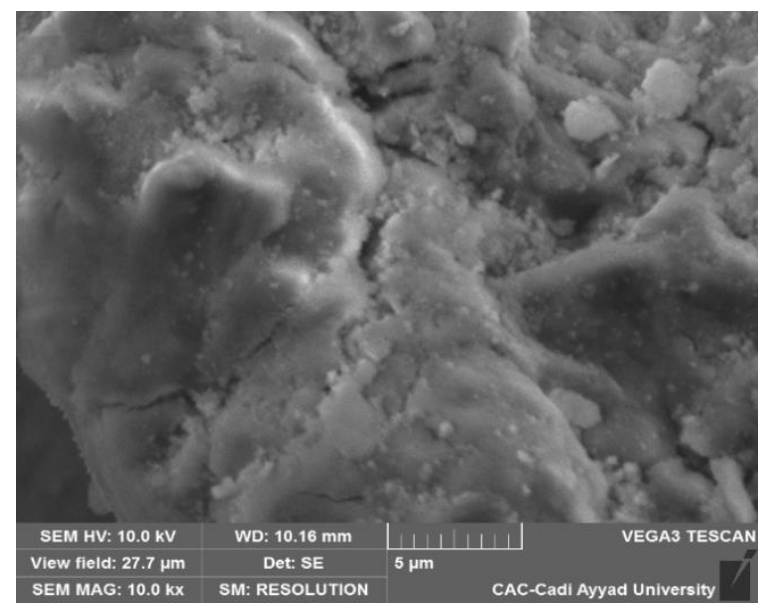

beads surface (Fig. 5b). These results supposed that the adsorption of $\mathrm{Cr}$ (III) ions by PANa occurred through a cationic exchange mechanism, which is in a good agreement with the results obtained with the IR spectra.

Figure 4. SEM micrographs of dry PANa beads before (a) and after (b) adsorption of chromium ions
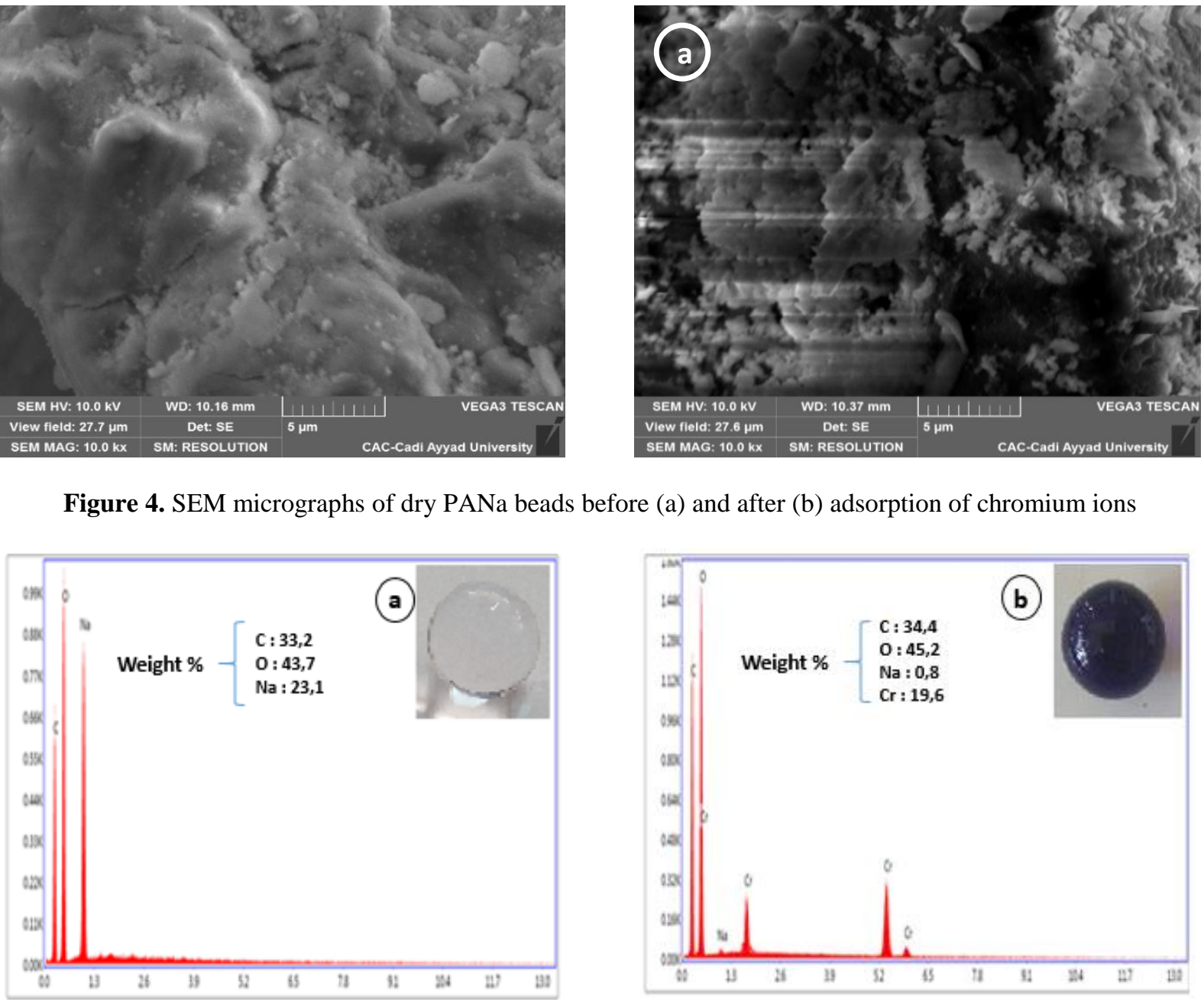

Figure 5. EDAX spectra of dry PANa beads before (a) and after (b) adsorption of chromium ions

\section{Effect of contact time}

The study of the evolution of chromium concentration versus time is an essential step for defining the optimal contact time necessary to reach the equilibrium of adsorption. Therefore, Fig. 6 represents the variation of $\mathrm{Cr}(\mathrm{III})$ concentration and aqueous solution $\mathrm{pH}$. It appears from the obtained results a significant and rapid decrease during the first 20 minutes of the experiment. This may be due to the availability of readily accessible active sites on the adsorbent surface ${ }^{30,31}$. At 60 minutes of contact between PANa beads and aqueous solution, the equilibrium was obtained due to the saturation of the functional groups $\left(-\mathrm{COO}^{-}\right)$by chromium ions ${ }^{32}$ where about $89 \%$ of chromium has been removed. 


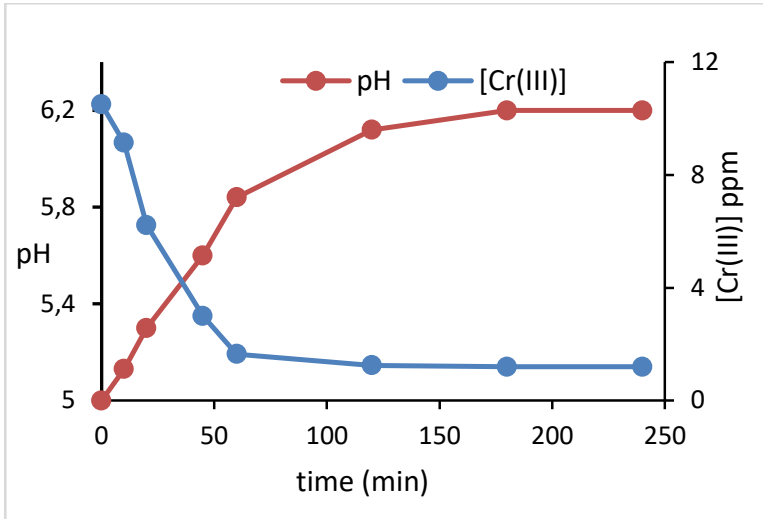

Figure 6. Effect of contact time on the adsorption of $\mathrm{Cr}$ (III) by PANa beads

Fig. 6 has shown that the decrease in the metal concentration ranging from $10.5 \mathrm{ppm}$ to $1 \mathrm{ppm}$ with the increase of $\mathrm{pH}$ values attaining 6.2 at the system equilibrium. Thus, PANa beads react with the aqueous solution by fixing the $\mathrm{H}_{3} \mathrm{O}^{+}$protons and $\mathrm{Cr}$ (III) ions and by releasing $\mathrm{Na}^{+}$ions according to an ion exchange process.

\section{Effect of solution $\mathrm{pH}$}

The presence of hydrogen ions in the solution has a significant influence on the removal process of heavy metals in aqueous solutions, as it affects the adsorbent surface charge, the solubility of the metal ions in the solution and the degree of ionization of the adsorbate during the reaction ${ }^{33,34}$. For all these reasons, the effect of $\mathrm{pH}$ on the removal of $\mathrm{Cr}$ (III) ions by sodium polyacrylate beads was studied for different $\mathrm{pH}$ values: 2,3 , 4, 4.5, 5, 5.5 and 6. Fig. 7 has shown a clear variation of extraction efficiency versus time. It was found that the removal percentage of metal ion increased from $5.5 \%$ to 90 $\%$ in increasing the $\mathrm{pH}$ from 2 to 4.5 . Afterwards, there is a slow increase in the removal efficiency with further increase in $\mathrm{pH}$. Up to $\mathrm{pH} 6$, chromium exists as $\mathrm{Cr}(\mathrm{OH})_{3}$ and forms an amorphous precipitate and therefore its sorption behaviour could not be studied ${ }^{35}$. Thus, the $\mathrm{pH}$ value of 5 was selected for the further studies. These results can be explained by the fact that at low values of the initial $\mathrm{pH}$, the surface of the adsorbent (PANa) is surrounded by $\mathrm{H}_{3} \mathrm{O}^{+}$protons, which would reduce the interaction of chromium with the active sites of the adsorbent, under the effect of repulsive forces ${ }^{36,37}$. However, after the increase of $\mathrm{pH}$ values, PANa beads surface was charged negatively through

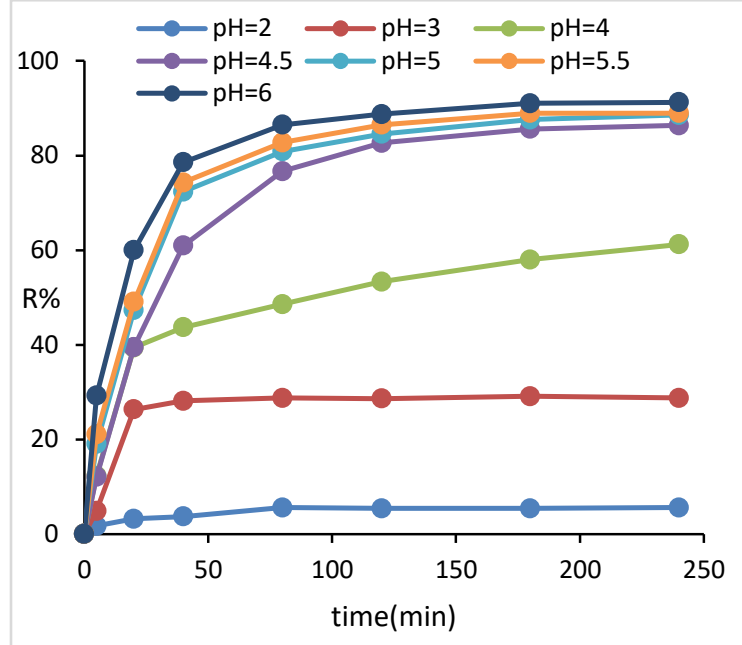

Figure 7. Effect of solution $\mathrm{pH}$ on the adsorption of Cr(III) by PANa beads

deprotonation of carboxyl groups $\left(\mathrm{COO}^{-}\right)$resulting in increased sorption ${ }^{38,39}$. The oxygen of each carbonyl and hydroxyl group is considered a strong Lewis base due to the presence of its vacant double electrons. Thanks to these doublets, the oxygen base forms a coordination complex with electron-poor $\mathrm{Cr}$ (III) ions. The dominant species of chromium in this $\mathrm{pH}$ range are $\mathrm{Cr}(\mathrm{OH})^{2+}{ }^{40}$. However, the spectroscopic study (Fig. 3) shows that the complexation of $\mathrm{Cr}(\mathrm{OH})^{2+}$ ions is according to the reaction $(\mathrm{Eq} 3)$ :

$2-\mathrm{COO}^{-}+\mathrm{Cr}(\mathrm{OH})^{2+} \rightarrow(-\mathrm{COO})_{2} \mathrm{Cr}(\mathrm{OH})(3)$

\section{Effect of adsorbent dose}

The study of the adsorbent influence dose on the adsorption process of chromium ions from aqueous solutions by PANa beads was effectuated. The evolution of adsorption efficiency of chromium ions by PANa beads with different adsorbent doses ranging from 0.01 to $0.1 \mathrm{~g}$ was followed. The measurement of the residual chromium concentration in the aqueous phase for each sample was carried out after 2 hours of contact, a time largely sufficient to reach equilibrium and at $\mathrm{pH}=5$. According to Fig. 8, the chromium removal rates increase with the increase of the adsorbent mass. At $60 \mathrm{mg}$ of PANa beads, the decontamination rate of the aqueous solution has reached $98.25 \%$ and the total purification is carried out with approximately $85 \mathrm{mg}$ of adsorbent polymer. This result can be explained by the increase of the extracting sites and the contact surface following the increase of the mass of the extractant support ${ }^{41}$. 


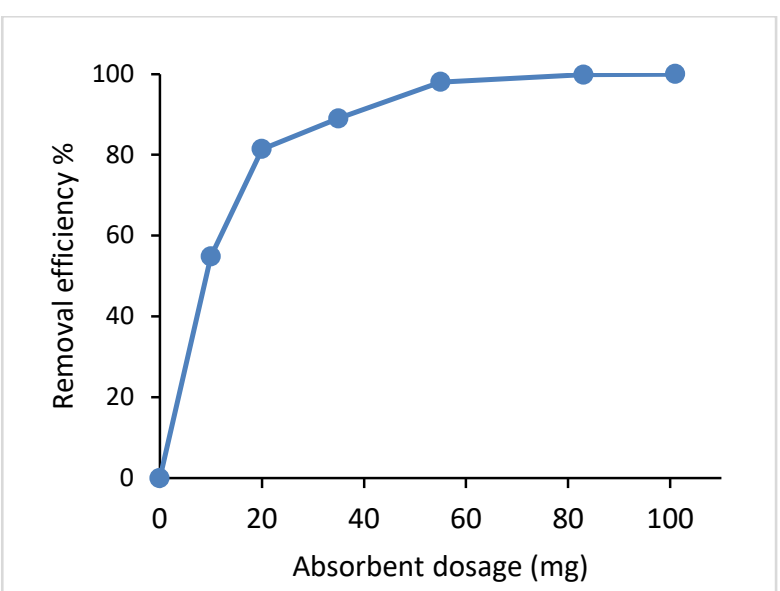

Figure 8. Effect of PANa beads mass on the adsorption process

\section{Effect of initial Cr(III) concentration}

The initial concentration of chromium ions had a considerable influence on the retention capacity of PANa beads ${ }^{42}$. Adsorption experiments were carried out under the same conditions previously defined, by varying the values of the initial concentration of the metal solution. The contact time of the adsorbent with the aqueous solution was set at 120 minutes and $\mathrm{pH}$ at 4.5. The evolution of the molar amount of chromium adsorption by the adsorbent versus initial heavy metal ions concentration was represented in Fig. 9.

The obtained results have shown that at low initial metal concentrations, the amount of chromium

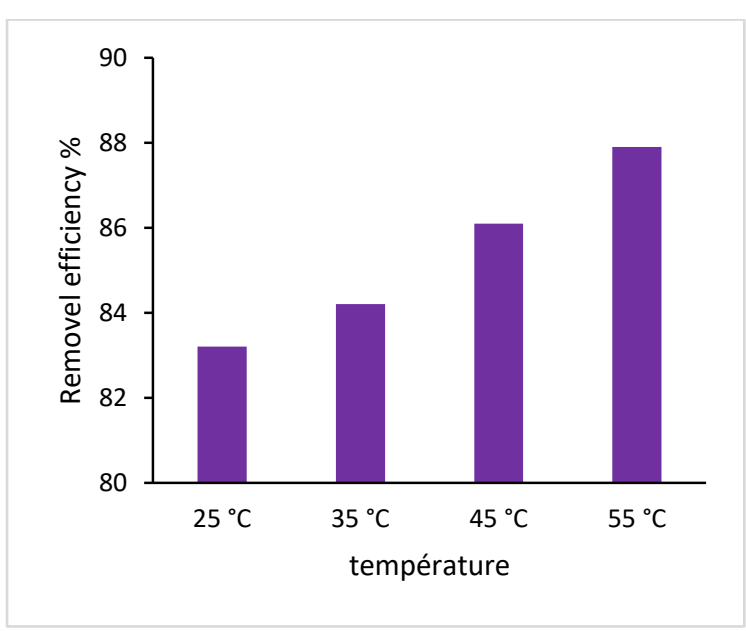

Figure 10. Effect of temperature on the adsorption of chromium ions by PANa beads

It appears from the obtained results (Fig. 10) that the temperature has an insignificant effect on the adsorption performance of $\mathrm{Cr}$ (III) by the hydrogel: The adsorption efficiency increases from 83.34 to $87.26 \%$ when the temperature increases from 25 to $55^{\circ} \mathrm{C}$. This slight variation is due to an increase of active sites on the PANa surface by stretching effect of the polymeric structure.

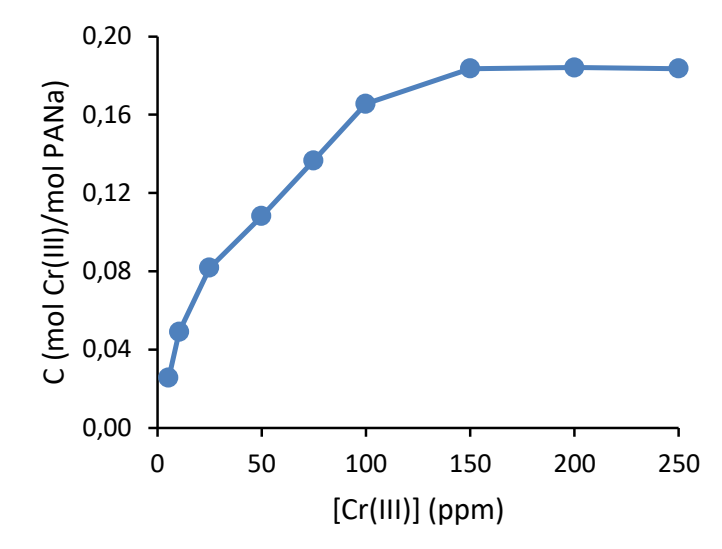

Figure 9. Effect of initial chromium ions on the adsorption process

retained by PANa beads increases rapidly and linearly as the concentration of chromium increases due to the increase in the driving force of the concentration gradient ${ }^{43}$. Above $150 \mathrm{ppm}$, the equilibrium was obtained corresponding to the saturation of the adsorbent with chromium ions attaining $0.18 \mathrm{~mol}$ of retained chromium/mole of dry polymer due to the high training force achieved by the strong tendency towards concentration ${ }^{44}$.

Effect of Temperature

The effect of temperature on the adsorption rate of $\mathrm{Cr}$ (III) by PANa beads was examined through temperature values ranging from 25 to $55{ }^{\circ} \mathrm{C}$. (Fig. 10).

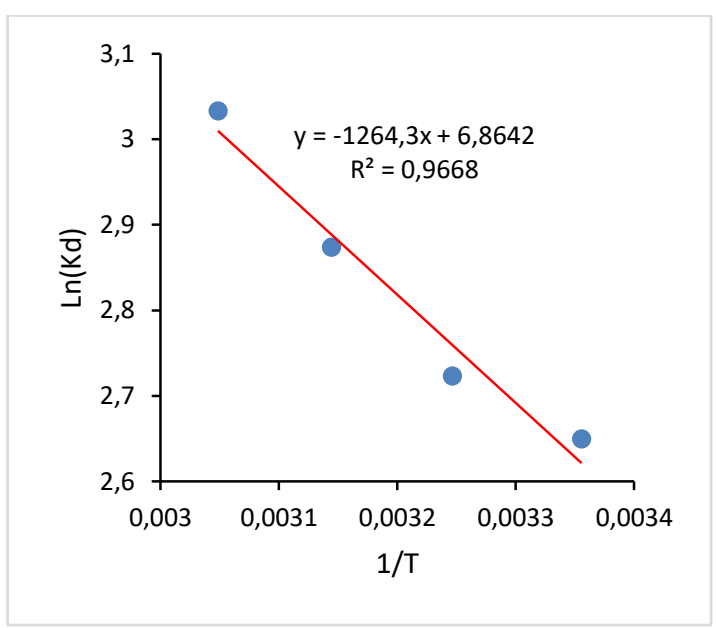

Figure 11. Van'tHoff curve corresponding to the adsorption of $\mathrm{Cr}(\mathrm{III})$ by PANa beads

\section{Thermodynamic study}

The thermodynamic parameters of chromium adsorption process on PANa beads can be calculated from the following relation ${ }^{45}$ (Eq. 4 and 5):

$\Delta \mathbf{G}^{\circ}=-\mathbf{R T}_{\ln K_{\mathrm{d}}}$

$\mathbf{K}_{\mathbf{d}}=\frac{Q_{e}}{C_{e}}$ 
Where Qe $\left(\mathrm{mg} \mathrm{g}^{-1}\right)$ is the amount of metal ion adsorbed at equilibrium, $\mathrm{Ce}\left(\mathrm{mg} \mathrm{L}^{-1}\right)$ is the concentration of heavy metal ions at the system equilibrium. $\Delta \mathbf{H}^{\circ}$ and $\Delta \mathbf{S}^{\circ}$ values were calculated from the slope and the intercept of the plot of $\ln \left(\mathrm{K}_{\mathrm{d}}\right)$ versus $1 /$ T (Fig. 11) by the (Eq. 6):

$\operatorname{Ln}\left(\mathbf{K}_{\mathrm{d}}\right)=-\frac{\Delta H^{0}}{R T}+\frac{\Delta S^{0}}{R}$
$\Delta \mathrm{G}^{0}, \Delta \mathrm{H}^{0}$ and $\Delta \mathrm{S}^{0}$ are related by the following equation $^{46}(\mathrm{Eq} .7)$ :

$\Delta G^{\circ}=\Delta H^{\circ}-T \Delta S^{\circ}$

Where $\mathrm{R}$ is the universal gas constant, $8.314 \mathrm{~J}$ $\mathrm{mol}^{-1} \mathrm{~K}^{-1}$ and $\mathrm{T}$ is the absolute temperature $(\mathrm{K})$ and $\mathrm{K}_{\mathrm{d}}$ is the thermodynamic equilibrium constant ( $\mathrm{L} \mathrm{g}^{-}$ $\left.{ }^{1}\right)$.

Table 1. Thermodynamic parameters of the adsorption process.

\begin{tabular}{|c|c|c|c|c|}
\hline $\mathbf{T}(\mathbf{K})$ & $\ln K_{d}\left(L g^{-1}\right)$ & $\Delta \mathrm{H}^{\circ}\left(\mathrm{kJ} \mathrm{mol}^{-1}\right)$ & $\Delta \mathbf{S}^{\circ}\left(\mathrm{J} \mathrm{mol}^{-1} \mathbf{K}^{-1}\right)$ & $\Delta \mathrm{G}^{\circ}\left(\mathrm{kJ} \mathrm{mol}^{-1}\right)$ \\
\hline 298 & 2.65 & 10.52 & 57.08 & -6.56 \\
\hline 308 & 2.72 & & & -6.97 \\
\hline 318 & 2.87 & & & -7.60 \\
\hline 328 & 3.03 & & & -8.27 \\
\hline
\end{tabular}

According to the thermodynamic parameters values obtained (Table 1 ), the positive value of $\Delta \mathrm{H}^{\circ}$ suggests that the adsorption of $\mathrm{Cr}$ (III) on PANa beads is an endothermic reaction. Negative values of $\Delta \mathrm{G}^{\circ}$ indicate that this adsorption has occurred through a spontaneous process $45,47,25$. While the positive value of $\Delta \mathrm{S}^{\circ}$ shows increased randomness at the $\mathrm{PANa} / \mathrm{metal}$ solution interface during adsorption ${ }^{48-50}$.

\section{Regeneration of adsorbent}

An effective adsorbent for the removal of heavy metals is one that has high removal efficiency as well as good desorption so that it can be recycled. Therefore, the study of the reversibility of the liquidgel system is very interesting. Indeed, the PANa beads charged with chromium ions $\left(1.7210^{-5} \mathrm{~mol}\right)$ was brought in contact with $40 \mathrm{ml}$ of $0.1 \mathrm{M}$ nitric acid at $25{ }^{\circ} \mathrm{C}$ and was stirred for $10 \mathrm{~min}$. Samples

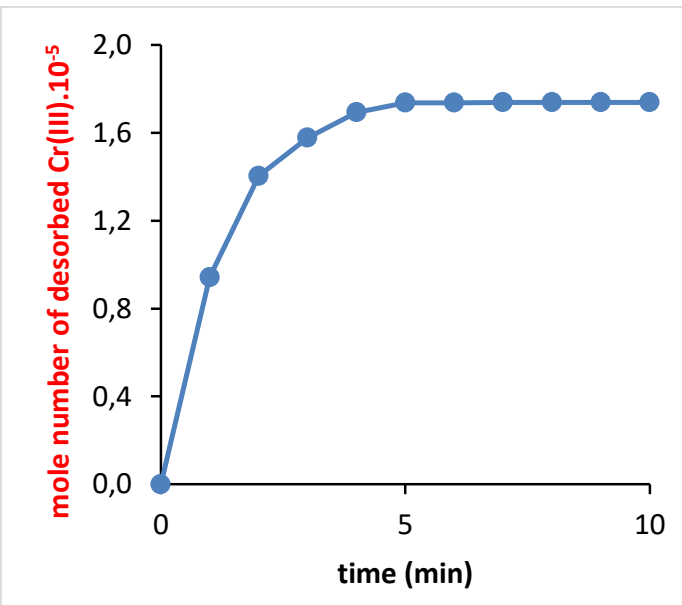

Figure 12. Desorption of chromium ions from PANa beads in $0.1 \mathrm{M} \mathrm{HNO}_{3}$ were taken from the acidic solution after each minute, diluted and then analysed.

Fig. 12 represents the variation in the mole number of chromium released in the acidic solution versus contact time, this mole number rapidly increases during the first 4 minutes, followed by the equilibrium of system where the amount of chromium recovered equal to the adsorbed one.

To test the recyclability of PANa beads, consecutive cycles of adsorption-desorption were repeated six times under the same conditions. The results of this study are illustrated in Fig. 13. It appears clear from these results that sodium polyacrylate beds retain their mechanical properties and their effectiveness despite a large number of uses. Overall results suggested that the studied adsorbent could be employed as a low-cost, sustainable, and excellent alternative material for $\mathrm{Cr}(\mathrm{III})$ ion removal from wastewater ${ }^{51}$.

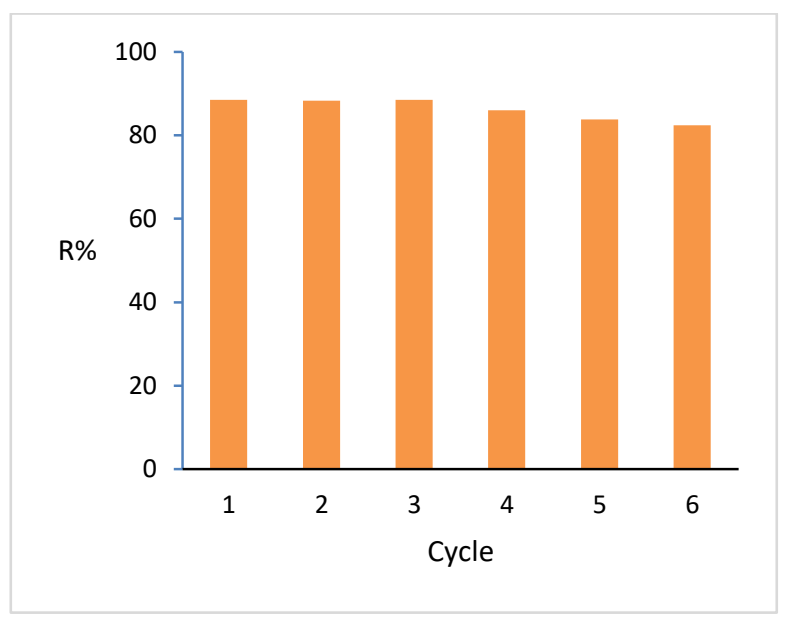

Figure 13. Adsorption / desorption cycles 


\section{Conclusion}

Sodium polyacrylate beads were investigated in the complexation of $\mathrm{Cr}$ (III) ions. On one hand, the characterization of the polymer by FTIR, SEM and EDAX techniques was effectuated. The adsorption performance of heavy metal ions by PANa beads depends essentially on the parameters related to the aqueous solution ( $\mathrm{pH}$, concentration, etc.). All results have shown that the adsorption equilibrium was reached after 60 minutes. The decrease in the concentration of chromium in the aqueous solution was accompanied by an increase in the $\mathrm{pH}$ values. This phenomenon is due to the acid-base rearrangement of the gel with the metal solution that results in the simultaneous consumption of protons $\mathrm{H} 3 \mathrm{O}+$ and $\mathrm{Cr}$ (III) by the polymeric support. Moreover, the obtained thermodynamic parameters have shown that the $\mathrm{Cr}$ (III) adsorption process on PANa is spontaneous and endothermic. Finally, the use of PANa beads for the removal of trivalent chromium by is an efficient technique due to the several advantages of this polymer.

\section{Acknowledgements}

The authors are pleased to acknowledge Ibn Tofail University faculty of sciences for providing the facilities for the research, especially the Director of Center of Analysis, Expertise, Transfer of Technology and Incubation (CUAE2TI), Kenitra. Also, authors express their gratitude to Center of Analysis and Characterization (CAC), Marrakech for the kind permission to use their facilities for the analysis.

\section{References}

1- P.A. Kobielska, A.J. Howarth, O.K. Farha, S. Nayak, Metal-organic frameworks for heavy metal removal from water, Coordination Chemistry Reviews, 2018, 358, 92-107.

2- X. Gong, D. Huang, Y. Liu, G. Zeng, R. Wang, J. Wei, C. Huang, P. Xu, J. Wan, C. Zhanga, Pyrolysis and reutilization of plant residues after phytoremediation of heavy metals contaminated sediments: For heavy metals stabilization and dye adsorption, Bioresource technology. 2018, 253, 64-71.

3- H. Kołoczek, J. Chwastowski, W. Żukowski, Peat and coconut fiber as biofilters for chromium adsorption from contaminated wastewaters, Environ. Sci. Pollut. Res., 2016, 23, 527-534.

4- J. Chwastowski, P. Staroń, H. Kołoczek, M. Banach, Adsorption of hexavalent chromium from aqueous solutions using Canadian peat and coconut fiber. Journal of Molecular Liquids, 2017, 248, 981-989.

5- P.A. Kumar, M. Ray, S. Chakraborty, Hexavalent chromium removal from wastewater using aniline formaldehyde condensate coated silica gel.
Journal of Hazardous Materials, 2007, 143, 24 32.

6- D. Basketter, D. Slodovnik, S. Merimes, A. Trattner, A. Ingber, Investigation of the threshold for allergic reactivity to chromium, Contact Dermatitis, 2000, 44, 70-74.

7- A. D. Dayan, A. J. Paine, Mechanisms of chromium toxicity, carcinogenicity and allergenicity: review of the literature from 1985 to 2000. Hum. Exp. Toxicol, 2001, 20, 439-451.

8- A. Pechova, A. Pavlata, Chromium as an essential nutrient: a review. Veterinarni medicina-praha-, 2007, 52, 1-18.

9- E. E. Roginski, W. Mertz, Effects of chromium (III) supplementation on glucose and amino acid metabolism in rats fed a low protein diet, Journal of nutrition, 1969, 97, 525-530.

10-E. M. Hamilton, S. D. Young, E. H. Bailey, M. J. Watts, Chromium speciation in foodstuffs: a review, Food Chemistry, 2018, 250, 105-112.

11-S. Abbasi, A. Bahiraei, Ultra trace quantification of chromium (VI) in food and water samples by highly sensitive catalytic adsorptive stripping voltammetry with rubeanic acid, Food chemistry, 2012, 133, 1075-1080.

12-F. Veglio, R. Quaresima, P. Fornari, S. Ubaldini, Recovery of valuable metals from electronic and galvanic industrial wastes by leaching and electrowinning. Waste Management, 2003, 23, 240-252.

13-C. Volzone, L. B. Garrido, Use of modified hydroxy-aluminum bentonites for chromium (III) removal from solutions, Journal of environmental management, 2008, 88, 1640-1648.

14- V. J. Inglezakis, M. D. Loizidou, H. P. Grigoropoulou, Ion exchange of $\mathrm{Pb}^{2+}, \mathrm{Cu}^{2+}, \mathrm{Fe}^{3+}$, and $\mathrm{Cr}^{3+}$ on natural clinoptilolite: selectivity determination and influence of acidity on metal uptake, Journal of Colloid and Interface Science, 2003, 261, 49-54.

15-S. K. Sahu, P. Meshram, B. D. Pandey, V. Kumar, T. R. Mankhand, Removal of chromium (III) by cation exchange resin, Indion 790 for tannery waste treatment, Hydrometallurgy, 2009, 99, 170-174.

16-H. Li, J. Li, Z. Chi, W. Ke, Kinetic and equilibrium studies of chromium (III) removal from aqueous solution by IRN-77 cationexchange resin, Procedia Environmental Sciences. 2012, 16, 646-655.

17-J. Guo, Q. Zhang, Z. Cai, K. Zhao, Preparation and dye filtration property of electrospun polyhydroxybutyrate-calcium alginate/carbon nanotubes composite nanofibrous filtration membrane, Separation and Purification Technology, 2016, 161, 69-79.

18-A. K. Golder, A. N. Samanta, S. Ray, Removal of trivalent chromium by electrocoagulation. Separation and purification technology, 2007, 53, 33-41. 
19-M. Ilou, F. Abida, Z. Hatim, A. Kheribech, Removal of heavy metals from synthetic solution by electrocoagulation. Mediterranean Journal of Chemistry, 2016, 5, 521-527.

20-Li H., Liu S., Zhao J., and Feng N., Removal of reactive dyes from wastewater assisted with kaolin clay by magnesium hydroxide coagulation process. Colloids and Surfaces A:

Physicochemical and Engineering Aspects, 2016, 494, 222-227.

21-S. S. Salih, T. K. Ghosh, Preparation and Characterization of Chitosan-Coated Diatomaceous Earth for Hexavalent Chromium Removal. Environmental Processes, 2018, 5, 23-39.

22-S. S. Salih, T. K. Ghosh, Highly efficient competitive removal of $\mathrm{Pb}$ (II) and $\mathrm{Ni}$ (II) by chitosan/diatomaceous earth composite. Journal of environmental chemical engineering, 2018, 6 , 435-443.

23-X. Chen, B. Zhang, Y. Liu, C. Zhao, H. Zhang, Q. Zhang, Effect of embedded sodium polyacrylate chains on the adsorption mechanism of neutral red by magnetic particles. Chemical Engineering Research and Design, 2017, 127, 223-235

24-S. S. Batool, Z. Imran, S. Hassan, K. Rasool, M. Ahmad, M.A. Rafiq, Enhanced adsorptive removal of toxic dyes using $\mathrm{SiO} 2$ nanofibers. Solid State Sciences, 2016, 55, 13-20.

25-A. Ouass, I. Ismi, H. Elaidi, A. Lebkiri, M. Cherkaoui, E. H. Rifi, Mathematical Modeling Of The Adsorption Of Trivalent Chromium By The Sodium Polyacrylate Beads , J. Mater. Environ. Sci., 2017, 8, 3448-3456.

26-O. F. Larsen, S. Woutersen, Vibrational relaxation of the $\mathrm{H}_{2} \mathrm{O}$ bending mode in liquid water, Journal of chemical physics, 2004, 121, 12143-12145.

27-E. Finocchio, E. Macis, R. Raiteri, G. Busca, Adsorption of trimethoxysilane and of 3-mercaptopropyltrimethoxysilane on silica and on silicon wafers from vapor phase: an IR study, Langmuir, 2007, 23, 2505-2509.

28-W. Wang, Y. Kang, A. Wang, One-step fabrication in aqueous solution of a granular alginate-based hydrogel for fast and efficient removal of heavy metal ions, Journal of Polymer Research, 2013, 20, 101-110.

29-I. Ismi, E. H. Rifi, , A. Lebkiri, H. Oudda, Spectral characterization of $\mathrm{PA}-\mathrm{Cu}$ under two polymeric forms and their complex $\mathrm{PA}-\mathrm{Cu}$, J. Mater. Environ. Sci, 2015, 6, 343-348.

30-A. Nasrullah, H. Khan, A. S. Khan, Z. Man, N. Muhammad, M. I. Khan, N. M. Abd ElSalam, Potential biosorbent derived from Calligonum polygonoides for removal of methylene blue dye from aqueous solution, The Scientific World Journal, 2015, Vol. 2015, ID: 562693.

31-T. Salman, F. A. Temel, N. G. Turan, Y. Ardali, Adsorption of lead (II) ions onto diatomite from aqueous solutions: Mechanism, isotherm and kinetic studies, Global NEST Journal, 2016, 18, 1-10.

32-Ş. Taşar, F. Kaya, A. Özer, Biosorption of lead (II) ions from aqueous solution by peanut shells: equilibrium, thermodynamic and kinetic studies, Journal of Environmental Chemical Engineering, 2014, 2, 1018-1026.

33-J. Li, Q. Lin, X. Zhang, Y. Yan, Kinetic parameters and mechanisms of the batch biosorption of $\mathrm{Cr}$ (VI) and $\mathrm{Cr}$ (III) onto Leersia hexandra Swartz biomass, Journal of Colloid and interface Science, 2009, 333, 71-77.

34-D. Lu, Q. Cao, X. Li, X. Cao, F. Luo, W. Shao, Kinetics and equilibrium of $\mathrm{Cu}$ (II) adsorption onto chemically modified orange peel cellulose biosorbents, Hydrometallurgy, 2009, 95, 145-152.

35-S. H. Shaikh, S.A. Kumar, Polyhydroxamic acid functionalized sorbent for effective removal of chromium from ground water and chromic acid cleaning bath, Chemical Engineering Journal, 2017, 326, 318-328.

36- A. B. Pérez-Marín, V. M. Zapata, J. F. Ortuno, M. Aguilar, J. Sáez, M. Lloréns, Removal of cadmium from aqueous solutions by adsorption onto orange waste, Journal of hazardous materials, 2007, 139, 122-131.

37-T. Ngulube, J. R. Gumbo, V. Masindi, A. Maity, An update on synthetic dyes adsorption onto clay based minerals: A state-of-art review, Journal of environmental management, 2017, 191, 35-57.

38-V. Bekiari, P. Lianos, Poly (sodium acrylate) hydrogels as potential $\mathrm{pH}$-sensitive sorbents for the removal of model organic and inorganic pollutants from water, Global Nest Journal, 2010, 12, 262-269.

39-N. Benzidia, A. Salhi, S.Bakkas, L.Khamliche, Biosorption of Copper $\mathrm{Cu}$ (II) in aqueous solution by chemically modified crushed marine algae (Bifurcaria bifurcata): Equilibrium and kinetic studies. Mediterranean Journal of Chemistry, 2015, 4, 85-92.

40-Z. Li, Q. Tang, T. Katsumi, X. Tang, T. Inui, S. Imaizumi, Leaf char: an alternative adsorbent for Cr (III). Desalination, 2010, 264, 70-77.

41-S. Kaur, S. Rani, R. K. Mahajan, Adsorption kinetics for the removal of hazardous dye congo red by biowaste materials as adsorbents, Journal of Chemistry, 2012, 2013, ID: 628582

42-S. H. Abbas, W. H. Ali, Evaluation of biomass type blue Cyanophyta algae for the sorption of $\mathrm{Cr}$ (III), Zn (II) and Ni (II) from aqueous solution using batch operation system: Equilibrium, kinetic and thermodynamic studies, Global Nest Journal, 2018, 20, 69-82.

43-I. Enniya, L. Rghioui, A. Jourani, Adsorption of hexavalent chromium in aqueous solution on activated carbon prepared from apple peels, Sustainable Chemistry and Pharmacy, 2018, 7 , 9-16. 
44-L. Kadiri, A. Lebkiri, E. H. Rifi, A. Ouass, Y. Essaadaoui, I. Lebkiri, H. Hamad, Kinetic studies of adsorption of $\mathrm{Cu}$ (II) from aqueous solution by coriander seeds (Coriandrum Sativum). In : E3S Web of Conferences. EDP Sciences, 2018, 02005.

45- A. Ramesh, D. J. Lee, J. W. C. Wong, Thermodynamic parameters for adsorption equilibrium of heavy metals and dyes from wastewater with low-cost adsorbents, Journal of Colloid and Interface Science, 2005, 291, 588-592.

46-S. S. Salih, T. K. Ghosh, Preparation and characterization of bioadsorbent beads for chromium and zinc ions adsorption. Cogent Environmental Science, 2017, 3, 1401577.

47-S. Wu, K. Zhang, J. He, X. Cai, K. Chen, Y. Li, B. Sun, L. Kong, J. Liu, High efficient removal of fluoride from aqueous solution by a novel hydroxyl aluminum oxalate adsorbent, Journal of colloid and interface science, 2016, 464, 238-245.
48-L. Li, F. Liu, H. Duan, X. Wang, J. Li, Y. Wang, C. Luo, The preparation of novel adsorbent materials with efficient adsorption performance for both chromium and methylene blue, Colloids and Surfaces B: Biointerfaces, 2016, 141, 253-259.

49-L. Kadiri, M. Galai, M. Ouakki, Y. Essaadaoui, A. Ouass, M. Cherkaoui, E. H. Rifi, A. Lebkiri, Coriandrum Sativum. L Seeds Extract as a Novel Green Corrosion Inhibitor for Mild Steel in 1.0 M Hydrochloric and 0.5 M Sulfuric Solutions, Anal. Bioanal. Electrochem, 2018, 10, 249-268.

50-Y. Essaadaoui, A. Lebkiri, E. H. Rifi, L. Kadiri, A. Ouass, Adsorption of lead by modified Eucalyptus camaldulensis barks: equilibrium, kinetic and thermodynamic studies. Desalination and Water Treatment. 2018, 111, 267-277.

51-S. S. Salih, T. K. Ghosh, Adsorption of Zn (II) ions by chitosan coated diatomaceous earth. International journal of biological macromolecules, 2018, 106, 602-610. 